\title{
PENGARUH TAMBAHAN PENGHASILAN DAN KOMITMEN ORGANISASIONAL TERHADAP SEMANGAT KERJA APARATUR SIPIL NEGARAPADA DINAS PENGENDALIAN PENDUDUK, KB, KEPENDUDUKAN DAN PENCATATAN SIPIL PROVINSI SUMATERA BARAT
}

\author{
Henny Sjafitri ${ }^{1)}$, Ramadhania $^{2)}$, Meugah Fauziah $^{3)}$ \\ sjafitrihenny@gmail.com ${ }^{1)}$, ramadhania010589@gmail.com ${ }^{2)}$, \\ meugahfauziah231080@gmail.com ${ }^{3)}$ \\ Fakultas Ekonomi Universitas Tamansiswa Padang ${ }^{1,2,3)}$
}

\begin{abstract}
The purpose of this study is to investigate and analyze the effect of additional income and organizational commitment on the morale of the state civil apparatus in the Population Control Office, Family Planning, Population and Civil Registry of West Sumatra Province. The research method used is descriptive quantitative. The population in this study amounted to 51 and the sample in this study amounted to 51 respondents. While the data analysis technique used in this study is the t test, $F$ test and the coefficient of determination. The results of the study show that additional income $(X 1)$ and organizational commitment (X2) together affect work morale. This can be seen from the value of $F_{-}$count $>F_{-}$table or 26.836>3.06 and a significant level $=0.000<0.05$ then Ho is rejected and Ha is accepted, with Adjusted $R$ Square value $=0$, 508. This means $50.8 \%$ of the variable additional income (X1) and organizational commitment (X2) together affect morale. While the remaining $49.2 \%$ is influenced by other variables not used in this study such as adequate salary, meeting spiritual needs, creating a relaxed atmosphere at work and others.
\end{abstract}

Keywords: Additional Income, Organizational Commitment and Work Spirit

Abstrak : Tujuan dari penelitian ini adalah untuk mengetahui dan menganalisa pengaruh tambahan penghasilan dan komitmen organisasional terhadap semangat kerja aparatur sipil negara pada Dinas Pengendalian Penduduk, KB, Kependudukan dan Pencatatan Sipil Provinsi Sumatera Barat. Metode penelitian yang digunakan adalah kuantitatif deskriptif. Populasi dalam penelitian ini berjumlah 51 dan sampel dalam penelitian ini berjumlah 51 responden. Sedangkan teknik analisa data yang digunakan dalam penelitian ini adalah uji t, uji $\mathrm{F}$ dan koefisien determinasi. Hasil penelitian terlihat bahwa tambahan penghasilan (X1) dan komitmen organisasional (X2) secara bersama-sama berpengaruh terhadap semangat kerja. Hal ini terlihat dari nilai $F_{\text {hitung }}>F_{\text {tabel }}$ atau 26,836 $>3,06$ dan tingkat signifikan $=0,000<0,05$ maka Ho di tolak dan Ha diterima, dengan nilai Adjusted $R$ Square $=0$, 508. Hal ini berarti sebesar 50,8\% variabel tambahan penghasilan (X1) dan komitmen organisasional (X2) secara bersama-sama mempengaruhi semangat kerja. Sedangkan sisanya 49,2\% dipengaruhi oleh variabel lainnya yang tidak digunakan dalam penelitian ini seperti gaji yang cukup, pemenuhan kebutuhan rohani, terciptanya suasana santai dalam bekerja dan lain-lain.

Kata kunci : Tambahan Penghasilan, Komitmen Organisasional dan Semangat Kerja.

\section{A. PENDAHULUAN}

Aparatur sipil negara sebagai unsur utama sumber daya manusia yang mempunyai peranan penting dalam menentukan keberhasilan penyelenggaraan pemerintahan dan pembangunan yang sangat strategis. Dalam melaksanakan tugas pemerintahan dan kinerja yang diberikan, apartur sipil negara menjadi sorotan atau suatu acuan bagi kinerja pemerintahan. 
Dalam pemerintahan, aparatur sipil negara selain menerima kompensasi langsung berupa upah/gaji pokok dan tunjangan kesejahteraan juga menerima insentif yaitu balas jasa selain gaji yang diberikan guna meningkatan motivasi dan semangat kerja, yang dalam penerapannya memakai bermacam istilah yaitu remunerasi, tunjangan kinerja dan tambahan penghasilan pegawai.

Pada Dinas PPKBKPS Provinsi Sumatera Barat, pemberian tambahan penghasilan yang diberikan kepada aparatur sipil negara tiap bulannya mengalami tingkat yang berbeda-beda terdapat peningkatan dan penurunan. Terjadinya peningkatan dan penurunan dikarenakan adanya faktor dari perilaku kerja dan prestasi kerja dari aparatur sipil negara tersebut.

Seperti masih adanya pegawai yang kurang disiplin dalam kehadiran, baik itu terlambat atau tidak masuk kantor tanpa izin pimpinan, dan keterlambatan dalam penyampaian laporan harian yang merupakan laporan hasil kinerja aparatur sipil negara selama satu bulan.

Tabel 1.2 Rekap Daftar Penerimaan Tambahan Penghasilan ASN pada Dinas PPKBKPS Provinsi Sumatera Barat periode Januari s.d Desember 2018.

\begin{tabular}{|l|l|c|c|c|}
\hline No & Bulan & $\begin{array}{c}\text { TPD } \\
\text { (Tambahan } \\
\text { Penghasilan } \\
\text { Dasar) }\end{array}$ & $\begin{array}{c}\text { TPK } \\
\text { ( Tambahan } \\
\text { Penghasilan } \\
\text { Kinerja) }\end{array}$ & $\begin{array}{c}\text { Jumlah } \\
\text { Penerimaan }\end{array}$ \\
\hline 1 & Januari & 44.556 .300 & 41.365 .250 & .85 .921 .550 \\
\hline 2 & Febr & 42.838 .100 & 41.262 .181 & .84 .100 .281 \\
\hline 3 & Maret & 43.978 .600 & .41 .953 .449 & .86 .276 .764 \\
\hline 4 & April & 46.865 .000 & .43 .731 .967 & .90 .596 .967 \\
\hline 5 & Mei & 46.865 .000 & .43 .731 .967 & .90 .596 .967 \\
\hline 6 & Juni & 47.435 .000 & .43 .947 .517 & .90 .932 .517 \\
\hline 7 & Juli & 47.435 .000 & .44 .628 .104 & .92 .063 .104 \\
\hline 8 & Agust & 48.005 .000 & .45 .010 .343 & .93 .015 .343 \\
\hline 9 & Sept & 47.435 .000 & .45 .203 .210 & .92 .638 .210 \\
\hline 10 & Okt & 45.145 .000 & .43 .375 .145 & .88 .523 .145 \\
\hline 11 & Nov & 67.252 .700 & .64 .268 .674 & 131.521 .374 \\
\hline 12 & Des & 69.060 .500 & .68 .322 .577 & 137.383 .077 \\
\hline
\end{tabular}

Sumber : Bagian Umum dan Kepegawaian Dinas PPKBKPS, 2018

Salah satu keberhasilan manajemen perusahaan adalah kemampuannya dalam menumbuhkan komitmen organisasional pegawai. Seberapa jauh komitmen organisasional pegawai terhadap perusahaan akan sangat menentukan pencapaian tujuan perusahaan. Hal ini sangat penting karena pegawai yang memiliki komitmen organisasional terhadap perusahaan akan menampilkan kinerja terbaiknya serta produktif dalam mejalankan pekerjaan. Bahkan sebagai salah satu syarat mutlak dalam memegang jabatan manajerial.

Berdasarkan hasil obervasi awal yang peneliti lakukan pada Dinas PPKBKPS Provinsi Sumatera Barat komitmen organisasional aparatur sipil negara terlihat kurang bagus, karena adanya ketidaknyamanan yang dirasakan. Hal ini terlihat dengan adanya aparatur sipil negara pegawai yang mutasi keluar ke instansi lain. Selain itu, masih ada aparatur sipil negara yang berkeinginan untuk keluar dengan adanya pengajuan surat permohonan pindah dan ada yang telah melakukan tes penerimaan untuk di tempatkan pada instansi lain.

Ketidaknyamanan yang dirasakan oleh aparatur sipil negara tersebut dipengaruhi oleh faktor emosional diantaranya sikap sesama aparatur sipil negara yang kurang kerjasama dalam melaksanakan pekerjaan dan pergaulan yang tidak harmonis, dan juga 
gaya kepemimpinan yang tidak bisa menghargai bawahan serta membentuk kotak-kotak diantara pegawai menjadi alasan moral serta etika dalam kenyamanan bekerja.

\section{Tabel 1.3 Daftar Mutasi ASN Dinas PPKBKPS Provinsi Sumatera Barat per} Januari 2017 s.d Desember 2018.

\begin{tabular}{|l|l|l|l|l|}
\hline No & \multicolumn{1}{|c|}{ Tahun } & $\begin{array}{c}\text { Jumlah } \\
\text { Pegawai }\end{array}$ & $\begin{array}{c}\text { Mutasi } \\
\text { ASN } \\
\text { Masuk }\end{array}$ & $\begin{array}{c}\text { Mutasi } \\
\text { ASN } \\
\text { Keluar }\end{array}$ \\
\hline 1 & Januari 2017 & 45 orang & 6 orang & 2 orang \\
\hline 2 & $\begin{array}{l}\text { Desember } \\
2018\end{array}$ & 51 orang & 5 orang & 3 orang \\
\hline
\end{tabular}

Sumber : Bagian Umum dan Kepegawaian Dinas PPKBKPS, 2018

Berdasarkan data diatas nampak terjadi mutasi pegawai masuk ke Dinas PPKBKPS Provinsi Sumatera Barat, selama 2 tahun sebanyak 11 orang, dan merupakan aparatur sipil negara yang berpindah dari Kabupaten/Kota ke Provinsi Sumatera Barat sedangkan mutasi pegawai keluar atau pindah ke instansi lain yang berpindah untuk promosi dan berpindah tugas biasa sebanyak 5 orang, mutasi pegawai keluar adalah keinginan dan kemauan dari diri sendiri aparatur, karena dalam instansi pemerintah Provinsi Sumatera Barat tidak ada perpindahan yang di lakukan oleh pihak pimpinan semua adalah atas permohonan dari aparatur sipil negara.

Di dalam melaksanakan pekerjaan, pegawai tidak akan terlepas dari semangat kerja yang merupakan salah satu hal yang mendorong seseorang bertindak untuk melaksanakan pekerjaan dengan baik. Seorang pegawai yang memiliki semangat kerja yang baik tentunya akan memberikan sikap yang positif dalam pekerjaan seperti kesetiaan, kegembiraan, kerjasama, kebanggaan dalam dinas dan ketaatan dalam kewajiban.

Berdasarkan pengamatan dilapangan yang penulis lihat, semangat kerja dari aparatur sipil negara pada Dinas PPKBKPS Provinsi Sumatera Barat masih termasuk rendah karena dapat dilihat dari aktifitas setiap pagi hari ada beberapa pegawai yang tidak langsung bekerja.

Aparatur sipil negara yang memiliki semangat yang tinggi akan lebih berkualitas dan mempunyai integritas yang tinggi serta nilai akuntabilitas yang baik bagi instansinya. Sebaliknya, aparatur sipil negara yang tidak bersemangat akan membawa pengaruh negatif bagi aparatur lainnya dan ini merupakan permasalahan dalam pencapai tujuan organisasi.

Berdasarkan uraian di atas maka penulis tertarik untuk melakukan penelitian lebih lanjut untuk mengkaji secara lebih mendalam mengenai "Pengaruh Tambahan Penghasilan dan Komitmen Organisasional Terhadap Semangat Kerja Aparatur Sipil Negara Pada Dinas PPKBKPS Provinsi Sumatera Barat."

\section{Rumusan Masalah}

1. Apakah tambahan penghasilan berpengaruh terhadap semangat kerja aparatur sipil negara pada Dinas PPKBKPS Provinsi Sumatera Barat?

2. Apakah komitmen organisasional berpengaruh terhadap semangat kerja aparatur sipil negara pada Dinas PPKBKPS Sipil Provinsi Sumatera Barat ?

3. Apakah pemberian tambahan penghasilan dan komitmen organisasional berpengaruh semangat kerja aparatur sipil negara pada Dinas PPKBKPS Provinsi Sumatera Barat? 


\section{Tujuan Penelitian}

1. Untuk mengetahui dan menganalisis pengaruh tambahan penghasilan terhadap semangat kerja aparatur sipil negara pada Dinas PPKBKPS Provinsi Sumatera Barat.

2. Untuk mengetahui dan menganalisis pengaruh komitmen organisasional terhadap semangat kerja aparatur sipil negara pada Dinas PPKBKPS Provinsi Sumatera Barat.

3. Untuk mengetahui dan menganalisis pengaruh tambahan penghasilan dan komitmen organisasional terhadap semangat kerja aparatur sipil negara pada Dinas PPKBKPS Provinsi Sumatera Barat.

\section{Manfaat Penelitian}

1. Bagi Penulis, diharapkan dapat berguna untuk menambah wawasan dan menerapkan teori yang di dapat dalam perkuliahan serta salah satu syarat untuk meraih gelar Strata 1 pada Universitas Tamansiswa Padang.

2. Bagi Instansi Tempat Penelitian, diharapkan dapat menjadi acuan dalam memberikan semangat bagi Aparatur Sipil Negara pada Dinas PPKBKPS Provinsi Sumatera Barat.

3. Bagi Akademis, agar dapat menjadi referensi untuk penelitian sejenis di kemudian hari.

\section{B. LANDASAN TEORI \\ Tambahan Penghasilan}

Menurut Priansa (2017:294), insentif yaitu penghargaan atau ganjaran yang diberikan untuk memotivasi para pekerja agar produktivitas kerjanya tinggi, sifatnya tidak tetap atau sewaktu-waktu

Menurut Simamora dalam Kadarisman (2016:182), mengemukakan kompensasi insentif (incentive compensation) adalah program-program kompensasi yang mengaitkan bayaran dengan produktivitas, insentif merupakan bentuk pembayaran langsung yang didasarkan atau dikaitkan langsung dengan kinerja dan gain sharing yang dengan kinerja dimaksudkan sebagai pembagian keuntungan bagi pegawai akibat peningkatan produktivitas atau penghematan biaya.

Menurut Nawawi (2016:317), menjelaskan insentif adalah penghargaan/ganjaran yang diberikan untuk memotivasi para pekerja agar produktivitas kerjanya tinggi, sifatnya tidak tetap atau sewaktu-waktu.

Menurut Kadarisman (2016:77) tujuan dari insentif yaitu :

1. Pemenuhan kebutuhan ekonomi

2. Meningkatkan produktivitas kerja

3. Memajukan organisasi atau perusahaan

4. Menciptakan keseimbangan dan keahlian

\section{Jenis Tambahan Penghasilan}

Menurut Peraturan Gubernur Nomor Nomor 12 Tahun 2015 yaitu :

1. Tambahan Penghasilan Dasar ( TPD )

Adalah komponen tambahan penghasilan yang menjadi tambahan penghasilan minimal yang diperoleh setiap pegawai sesuai ketentutan peraturan perundangundangan.

2. Tambahan Penghasilan Kinerja (TPK)

Adalah komponen tambahan penghasilan yang besarannya ditentukan berdasarkan hasil pengukuran kinerja. 


\section{Uang lembur}

Yaitu komponen tambahan penghasilan yang ditentukan berdasarkan jumlah jam bekerja di luar jam/ hari kerja.

4. Tambahan Penghasilan Pertimbangan Tertentu ( TPPT), merupakan komponen tambahan penghasilan yang besarannya di tentukan berdasarkan pertimbangan tempat tugas.

\section{Tipe Program Insentif} antara lain :

Ada beberapa tipe program insentif menurut Dessler dalam Iswanto (2016:633)

1. Insentif untuk karyawan operasional.

2. Insentif untuk manajer dan eksekutif.

3. Insentif untuk tenaga penjual.

4. Insentif organisasi.

\section{Indikator Tambahan Penghasilan}

Menurut Wibowo (2014:301) dapat diukur berdasarkan yaitu:

1. Keberhasilan kinerja mencapai tujuan adalah insentif berdasarkan keberhasilan mencapai tujuan dengan jumlah dan waktu yang telah ditentukan

2. Efisiensi biaya adalah insentif berdasarkan kenaikan produktivitas organisasi yang di rancang untuk menawarkan pekerja pembagian bersama setiap kenaikan produktivitas.

3. Keterampilan pekerja aalah insentif berdasarkan keterampilan yang di miliki secara mendasar.

\section{Komitmen Organisasional}

Menurut Priansa (2017:111), komitmen organisasional adalah loyalitas pegawai terhadap perusahaan, yang tercermin dari keterlibatannya yang tinggi untuk mencapai tujuan perusahaan.

Menurut Kreitner dan Kinicki (2016:166), komitmen organisasional adalah kesepakatan untuk melakukan sesuatu untuk diri sendiri, individu lain, kelompok atau organisasi.

\section{Prinsip Komitmen Organisasional}

Menurut Prinsa (2017:111), ada lima prinsip kunci dalam membangun komitmen organisasional oleh pimpinan yaitu :

1. Memelihara atau meningkatkan harga diri, artinya pimpinan harus pintar menjaga agar harga diri pegawai tidak rusak.

2. Memberikan tanggapan dengan empati, ikut merasakan terhadap apa yang di rasakan pegawai.

3. Meminta bantuan dan mendorong keterlibatan, yaitu selain ingin dihargai, pegawai juga ingin dilibatkan dalam pengambilan keputusan.

4. Mengungkapkan pikiran, perasaan dan rasional.

5. Memberikan dukungan tanpa mengambil alih tanggung jawab.

\section{Indikator Komitmen Organisasional}

Menurut Prinsa (2017:117), menyatakan ada tiga indikator komitmen organisasional yaitu :

a. Komitmen afektif (affective commitment).

b. Komitmen normatif (normative commitment).

c. Komitmen berkelanjutan (continuence commitment). 


\section{Semangat Kerja}

Menurut Nitisemoto (2015:160), semangat kerja adalah melakukan pekerjaan secara lebih giat, sehingga dengan demikian pekerjaan akan diharapkan lebih cepat dan lebih baik. Menurut Siagian (2010:57), menyatakan semangat kerja adalah sejauh mana karyawan bergairah dalam melakukan tugas dan tanggung jawab di dalam perusahaan.

\section{Faktor-Faktor Yang Mempengaruhi Semangat Kerja}

Menurut Nitisemoto (2015:167), faktor-faktor yang menyebabkan turunya semangat kerja adalah :

1. Upah yang terlalu rendah, pemberian upah/gaji yang tidak sesuai dengan pekerjaan yang diberikan.

2. Insentif yang kurang terarah, dimana insentif diberikan tidak sesuai dengan prestasi karyawan

3. Lingkungan kerja yang buruk, kegelisahan yang di sebabkan lingkungan yang buruk baik.

4. Ketidakpuasan karyawan terhadap perlakuan yang diterima,

\section{Indikator Semangat Kerja}

Menurut Nitisemito ( 2015:161 ), antara lain :

1. Naiknya produktivitas karyawan.

2. Tingkat absensi rendah,

3. Labour Turn Over,

4. Berkurangnya kegelisahan,

\section{METODELOGI PENELITIAN}

Jenis metode digunakan adalah metode penelitian kuantitatif

\section{Populasi dan Sampel}

Populasi dalam penelitian ini adalah seluruh Aparatur Sipil Negara pada Dinas PPKBKPS Provinsi Sumatera Barat dengan jumlah 51 orang. Pengambilan sampel dilakukan dengan metode sampling jenuh yaitu teknik penentuan sampel bila semua anggota populasi digunakan sebagai sampel (Sugiyono, 2018:140), yaitu sebanyak 51 orang Aparatur Sipil Negara.

Teknis analisis data yang digunakan adalah analisis regresi linear berganda, uji t, uji F, dan koefisien determinasi.

\section{HASIL DAN PEMBAHASAN}

\begin{tabular}{|c|c|c|c|c|c|c|}
\hline & & & $\begin{array}{l}\text { Hasil L } \\
\text { Coefficient }\end{array}$ & i $\mathbf{t}$ & & \\
\hline & & $\begin{array}{r}\text { Unstan } \\
\text { Coef }\end{array}$ & $\begin{array}{l}\text { dardized } \\
\text { icients }\end{array}$ & $\begin{array}{c}\text { Standardize } \\
d \\
\text { Coefficients }\end{array}$ & & \\
\hline & & $\bar{B}$ & Std. Error & Beta & $t$ & Sig. \\
\hline 1 & (Constant) & 9.649 & 3.128 & & 3.084 & .003 \\
\hline & $\begin{array}{l}\text { Tambahan } \\
\text { Penghasil } \\
\text { an }\end{array}$ & .608 & .132 & .496 & 4.619 & .000 \\
\hline & $\begin{array}{l}\text { Komitmen } \\
\text { Organisasi } \\
\text { onal }\end{array}$ & .358 & .103 & .374 & 3.478 & .001 \\
\hline
\end{tabular}




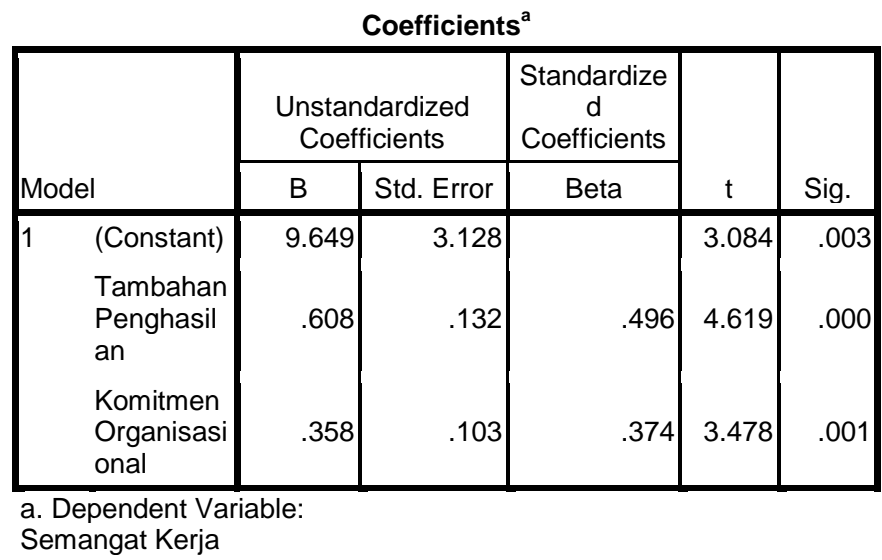

Sumber : Olahan Data Primer (2019)

1. Variabel pendidikan tambahan penghasilan $\left(\mathrm{X}_{1}\right)$ berpengaruh signifikan terhadap semangat kerja aparatur sipil negara pada Dinas PPKBKPS Provinsi Sumatera Barat. Hal ini terlihat dari nilai signifikan $0,000<0,05$ dan nilai $\mathrm{t}_{\text {tabel }} \mathrm{df}=\mathrm{n}-\mathrm{k}=51$ $3=48(1,677)$ serta juga dapat dilihat pada nilai $t_{\text {hitung }}>t_{\text {tabel }}(4,619>1,677)$ maka $\mathrm{H}_{\mathrm{o}}$ ditolak dan $\mathrm{H}_{\mathrm{a}}$ diterima.

2. Variabel komitmen organisasional $\left(\mathrm{X}_{2}\right)$ berpengaruh signifikan terhadap semangat kerja aparatur sipil negara pada Dinas PPKBKPS Provinsi Sumatera Barat. Hal ini dapat terlihat dari signifikan 0,001 $<0,05$ dan nilai $\mathrm{t}_{\text {tabel }} \mathrm{df}=\mathrm{n}-\mathrm{k}=51-3=48(1,677)$ dan dapat juga dilihat dari $\mathrm{t}_{\text {hitung }}>\mathrm{t}_{\text {tabel }}(3,478>1,677)$ maka $\mathrm{H}_{\mathrm{o}}$ ditolak dan $\mathrm{Ha}$ diterima.

Hasil Uji F

ANOVA $^{\text {b }}$

\begin{tabular}{|r|r|r|r|r|r|}
\hline Model & $\begin{array}{l}\text { Sum of } \\
\text { Squares }\end{array}$ & Df & $\begin{array}{r}\text { Mean } \\
\text { Square }\end{array}$ & F & Sig. \\
\hline $1 \quad \begin{array}{l}\text { Regr } \\
\text { essio } \\
\mathrm{n}\end{array}$ & 498.144 & 2 & 249.072 & 26.836 & $.000^{\mathrm{a}}$ \\
$\begin{array}{r}\text { Resid } \\
\text { ual }\end{array}$ & 445.503 & 48 & 9.281 & & \\
Total & 943.647 & 50 & & & \\
\hline
\end{tabular}

a. Predictors: (Constant), Komitmen Organisasional,

Tambahan Penghasilan

b. Dependent Variable:

Semangat Kerja

Sumber : Olahan Data Primer (2019)

Berdasarkan hasil pengujian pada Tabel 4.17 dapat diketahui bahwa nilai $\mathrm{F}_{\text {hitung }}$ sebesar 26,836 dengan $\mathrm{F}_{\text {tabel }} \mathrm{df}_{1}=\mathrm{k}-1=(3-1=2), \mathrm{df}_{2}=\mathrm{n}-\mathrm{k}(51-3=48)$ adalah 3,19 sehingga nilai $F_{\text {hitung }}>F_{\text {tabel }}$ atau 26,836 $>3,06$ dan tingkat signifikansi $0,000<0,05$ maka $\mathrm{H}_{\mathrm{o}}$ ditolak Ha diterima. Hal ini dapat disimpulkan bahwa variabel tambahan penghasilan dan komitmen organisasional secara bersamaan berpengaruh signifikan terhadap terhadap semangat kerja aparatur sipil negara pada Dinas PPKBKPS Provinsi Sumatera Barat. 


\title{
Uji Koefisien Determinasi $\left(\mathbf{R}^{2}\right)$
}

\author{
Hasil Uji Koefisien Determinasi \\ Model Summary

\begin{tabular}{|l|r|r|r|r|}
\hline Model & \multicolumn{1}{|c|}{$\mathrm{R}$} & R Square & $\begin{array}{c}\text { Adjusted R R } \\
\text { Square }\end{array}$ & $\begin{array}{c}\text { Std. Error } \\
\text { of the } \\
\text { Estimate }\end{array}$ \\
\hline 1 & $.727^{\mathrm{a}}$ & .528 & .508 & 3.047 \\
\hline
\end{tabular} \\ a. Predictors: (Constant), Komitmen Organisasional, \\ Tambahan Penghasilan \\ Sumber : Olahan Data Primer (2019)
}

Berdasarkan Tabel 4.18 dapat diketahui bahwa nilai koefisien determinasi sebesar 0,508. Hal ini terdapat hubungan antara variabel tambahan penghasilan dan komitmen organisasional terhadap semangat kerja aparatur sipil negara pada Dinas PPKBKPS Provinsi Sumatera Barat adalah sebesar 50,8\% sisanya 49,2\% dijelaskan oleh variabel lain yang tidak dibahas dalam penelitian ini yaitu gaji yang cukup, pemenuhan kebutuhan rohani, terciptanya suasana santai dalam bekerja, penempatan karyawan pada posisi yang tepat, fasilitas yang memadai

\section{E. KESIMPULAN}

Berdasrkan hasil penelitian dan pembahasan penelitian maka dapat di ambil kesimpulan adalah sebagai berikut :

a. Variabel Tambahan Penghasilan (X1) berpengaruh signifikan terhadap Semangat Kerja (Y) Aparatur Sipil Negara pada Dinas PPKBKPS Provinsi Sumatera Barat. Hal ini dibuktikan dengan nilai signifikansi $0,000<0,05$ dan $\mathrm{df}=\mathrm{n}-\mathrm{k}=51-3=48$ diperoleh $t_{\text {tabel }}$ sebesar 1,677 dan hasilnya $t_{\text {hitung }}>t_{\text {tabel }} 4,619>1,677$ maka Ho ditolak dan Ha diterima.

b. Variabel Komitmen Organisasional (X2) berpengaruh signifikan terhadap Semangat Kerja (Y) Aparatur Sipil Negara pada Dinas PPKBKPS Provinsi Sumatera Barat. Hal ini dibuktikan dengan nilai signifikansi $0,000<0,05$ dan $\mathrm{df}=\mathrm{n}-\mathrm{k}=51-3=48$ diperoleh $t_{\text {tabel }}$ sebesar 1,677 dan hasilnya $t_{\text {hitung }}>t_{\text {tabel }} 3,478>1,677$, maka Ho ditolak dan Ha diterima.

c. Variabel Tambahan Penghasilan (X1) dan Komitmen Organisasional (X2) secara bersama-sama berpengaruh signifikan terhadap Semangat Kerja (Y) Aparatur Sipil Negara pada Dinas PPKBKPS Provinsi Sumatera Barat. Hal ini dibuktikan dengan nilai signifikansi $0,000<0,05$ maka $\mathrm{H}_{\mathrm{o}}$ ditolak Ha diterima

d. Hasil uji koefisien determinasi dilihat dari nilai Adjusted $R$ Square $=0,508$. Hal ini berarti sebesar 50,8\% variabel Tambahan Penghasilan (X1) dan Komitmen Organisasional (X2) secara bersama-sama mempengaruhi variabel Semangat Kerja. Sedangkan sisanya 49,2\% dipengaruhi oleh variabel lainnya yang tidak digunakan dalam penelitian ini.

\section{Saran}

1) Dengan menganalisa tambahan penghasilan di harapkan standar pemberian tambahan penghasilan harus sesuai dengan tingkat keterampilan yang dimiliki oleh aparatur sipil negara dalam hal ini di harapkan adanya peningkatan demi mencukupi kebutuhan dan terciptanya masyarakat khususnya aparatur sipil negara yang lebih sejahtera. 
2) Dengan menganalisa komitmen organisasional diharapkan aparatur sipil negara tetap mempertahankan kepatuhan terhadap atasan dalam hal pelaksanaan perintah kedinasan sebagai bukti loyalitas terhadap negara dan juga pimpinan harus berusaha mengembangkan karir bawahan dengan memberikan kesempatan untuk memberikan informasi yang bisa menaikkan promosi bawahan pada dinas lain dilingkungan pemerintahan khususnya provinsi Sumatera Barat.

3) Diharapkan dengan menganalisa semangat kerja diharapkan aparatur sipil negara selalu menjaga kedisiplinan dalam kehadiran bukan hanya karena ketakutan pemotongan tambahan penghasilan akan tetapi berasal dari kebiasaan disiplin kerja. Juga pimpinan tidak membuat kebijakan yang mengikat aparatur sipil negara bagi yang ingin pindah ke dinas lain guna menambah wawasan dan pergaulan pada pemerintahan khususnya provinsi Sumatera Barat.

\section{F. DAFTAR PUSTAKA}

Iswanto,Yun, dan Adie Yusuf. 2016. Manajemen Sumber Daya Manusia. Cetakan Kedelapan. Banten : Penerbit Unversitas Terbuka.

Kadarisman, 2016. Manajemen Kompensasi. Cetakan Ke-3. Jakarta : Penerbit PT. Raja Grafindo Persada.

Kreitner, Robert dan Angelo Kinicki, 2010. Organizational Behavior. New York : McGraw-Hill

Nawawi, Hadari, 2016. Manajemen Sumber Daya Manusia untuk bisnis yang kompetitif, Cetakan Ke Sembilan.Yogyakarta: Penerbit gdjah Mada Unversity Press.

Nitisemoto, Alex S.2015. Manajemen Personalia Manajemen. Edisi Kedelapan. Jakarta : Ghalia Persada.

Peraturan Gubernur Provinsi Sumatera Barat Nomor 12 Tahun 2015, tentang Tambahan Penghasilan Bagi Pegawai di Lingkungan Pemerintah Provinsi Sumatera Barat.

Priansa, Donni Juni, 2017. Manajemen Kinerja Kepegawaian, Cetakan Ke-1. Bandung: Penerbit CV. Pustaka Setia.

Siagian, 2010. Manajemen Sumber Daya Manusia, Jakarta : Penerbit Bumi Aksara. Sugiyono, 2018. Metode Penelitian. Cetakan Ke-2. Bandung : Penerbit CV. Alfabeta. Wibowo, 2014. Manajemen Kinerja, Edisi Kempat. Jakarta: Penerbit Kharisma Putra Utama Offset 